\title{
Textbooks Weighing you Down? Check out our E-Readers
}

\author{
Sian Brannon and Suzanne Sears \\ University of North Texas Libraries, University of North Texas, Denton, TX
}

\begin{abstract}
The University of North Texas Libraries received a grant for e-book readers for students purchasing digital textbooks. The grant provided a way to access electronic information in the form of digital textbooks to those who wish to use them but could not afford to purchase ereaders. The university bookstore offers digital textbooks, but not many students have used them. Through administering the grant the authors learned how to implement and market the e-reader service and how students felt about the technology. Evaluation methodology included a pre- and post-test outcomes-based survey for students using the technology. Future considerations are also noted.
\end{abstract}

Keywords: e-readers, e-textbooks, academic library, University of North Texas, e-books

The University of North Texas (UNT) is a 4-year public university located in Denton, a city of approximately 117,000 people. UNT is the fourth largest university in Texas and among the 30 largest in the United States. The total student enrollment for 2012-2013 was 35,778, with the average age of undergraduates being 22.5 and 31.7 for graduate students (UNT, 2013). The UNT Libraries is the most used student service on campus, with more than 1.5 million in-person visitors during 2013. Statistics show that during the 2012-2013 academic year, over 54,000 laptops were checked out by students. UNT Libraries recently updated their collection-development policy to reflect a preference for e-books when available. The campus is catering more and more to distance-education students and witnessing an increase in technology use on campus as well.

Although continually being asked for textbooks by students using our libraries, many academic library (and public library, for that matter) collection-development policies purposefully eliminate the provision of textbooks to their communities. Unfortunately, the cost is prohibitive, as is dedicating shelving space for housing such an extensive collection. It is also hard to maintain the constant addition of new editions. One of our only methods of provision is to ask professors to donate a copy to the reserves shelf.

The UNT bookstore provides a digital textbook option for over 340 titles. These are available for purchase or rental. However, this service has not been used by many students. In 2012, only 428 digital textbooks were purchased by students. In pondering this low usage rate, the researchers wondered whether or not students had access to their own personal e-book readers, which would allow access to the materials. The low usage of these materials could be a result of multiple factors: preference for print over electronic, cost-prohibition, lack of access to the necessary technology, or other reasons. Being interested in electronic access to information, the researchers wanted to acknowledge the need for textbook provision and help those who do not have the means to purchase a personal reader. Through 
provision of the technological mechanism, we were able to alleviate some of the students' financial burden and explore whether e-readers were of interest to the students.

\section{LITERATURE REVIEW}

Research on e-readers and e-book usage both in general and in academic libraries exists in droves. For a detailed summation of the literature on e-readers in academic libraries up through 2010, consult Tees (2010). Otherwise, any search involving "e-book," "e-reader," or "digital textbook" in a library literature database will turn up dozens of articles about student attitudes, the future of textbooks, and the functionality of e-readers.

For a general picture of e-book reader usage across the country, one should consult numerous Pew Research Center studies which track both e-book and e-reader saturation into the American population. According to one such study conducted in 2012, one-third of Americans own an e-book reading device of some kind, and college degree holders are most likely to read e-books (Rainie \& Duggan, 2012). Also, e-readers are likely to be used by "younger, more educated, and higher income consumers" (Jung, ChanOlmsted, Park, \& Kim, 2011, p. 217).

Researchers have looked at adoption of e-readers in academic libraries and by college students for some time. Students seem to want to check out e-book devices from their schools (Foasberg, 2011), and faculty are incorporating them into coursework (de Oliveira, 2012). Texas A\&M University (Goodwin, Shurtz, Gonzalez, \& Clark, 2011), the University of Texas at San Antonio (Kemp, Lutz, \& Nurnberger, 2012), Penn State University (Behler, \& Lush, 2011), and the California Institute of Technology (McCaslin, 2013) have all studied the circulation of e-readers, with similar results. Students are interested in the devices and are happy the library is providing them, but the e-readers need to improve in ease of use, availability of content, and longer checkout times.

Some studies have targeted e-textbooks specifically. In Finland, researchers specifically used the Kindle for course materials in various classes and determined that while students liked having the devices, the functionality was subpar and needed to be improved before being adopted as a full-time textbook replacement (Ahlroos \& Hahto, 2012). Weisberg (2011) surveyed students longitudinally at his school and found that although students were more receptive each year to using digital textbooks and ereaders, they had no impact on student achievement. In the United Kingdom, researchers found that etextbooks are used more in newer schools, and that issues related to e-textbook use include lack of available titles, confusion due to multiple means of access, and a dearth of promotion of their availability (Nicholas, Rowlands, \& Jamali, 2010).

It is important to note the variations in findings in studies regarding the preference of e-books or ereaders over print. Some purport there is a preference toward print over electronic textbooks (Westfall, 2011), and that electronic versions of books are used only for "obtaining snippets of information and fact finding" rather than actual reading (Nicholas et al., 2010, p. 278). Others say that electronic versions of texts are used more in reserves compared to print versions (Rojeski, 2012). 
In early 2012, the Texas State Library and Archives Commission (TSLAC) solicited proposals for their "Impact Grants Program," which awards money to fund start-up programs at libraries within the state. Funded by the Library Services and Technology Act through the Institute of Museum and Library Services, the one-time grants are required to support new programs or improve existing ones. The programs funded have to relate to one of three general areas: technology skills for economic recovery, early childhood literacy for educational attainment, or electronic information technology.

This third category, electronic information technology, fit perfectly with what the UNT library wanted to provide for our students. In applying for the grant, we knew that we could not only fund e-readers, but provide an example for other libraries in relation to how to catalog and circulate technology and how to market a new service. We already had a successful technological circulation program with our provision of loaner laptops for students; providing e-book readers enhances this program, but also provides a direct link to a resource that many academic libraries are asked to provide-textbooks.

We submitted our grant application with the necessary materials: information about budget, timeline, community need, innovation, personnel, project activities, marketing, and sustainability. In summer of 2012 , we were awarded a $\$ 10,000$ grant to purchase and market e-readers for our campus. We did not set out to design an intense research project with control groups of students who had access to technology and groups who did not, nor did we develop concentrated usability testing of the devices themselves. Given the limited amount of funding and the constraints of the granting agency, we sought to explore the impact that the technology could potentially have on our students, with the option of expanding the project further pending final reports. In this article the authors present a case study for other academic libraries interested in implementing such a program.

\section{TIMELINE}

After notification of acceptance, implementation planning began in summer of 2012. Grant recipients held meetings with the head of technology and the public information officer of the library to review technological needs and plan the necessary publicity. As an academic institution, we are required to get approval to distribute surveys to students for all research involving human subjects. Coordinating this through the Texas State Library and Archives Commission (TSLAC) and our review board was challenging because of the survey instrument we were required to use by TSLAC. We were unsure if we would be able to get the research started on time because of the delay by the TSLAC and the institutional review board.

Researchers continued to participate in TSLAC webinars about administration of grants into the fall semester. Meanwhile, the public information office designed a campaign for marketing. In October of 2012, we approved marketing materials, created pre- and post-test surveys, and ordered equipment. We received approval from the Institutional Review Board to proceed with research. Equipment purchases were completed by December, 2012. At this time, training of staff began.

Circulation of equipment began in January of 2013, with all 20 e-readers being checked out within 4 days. Immediately after the launch, we were interviewed by the campus newspaper. Unfortunately, due to the lateness of the article in our marketing campaign, all e-readers were already checked out.

Students checked the e-readers out for an entire semester and were required to return them without an 
extension of checkout time. Pre- and post-test data were gathered and analyzed each semester. Following is a summary of our grant activities:

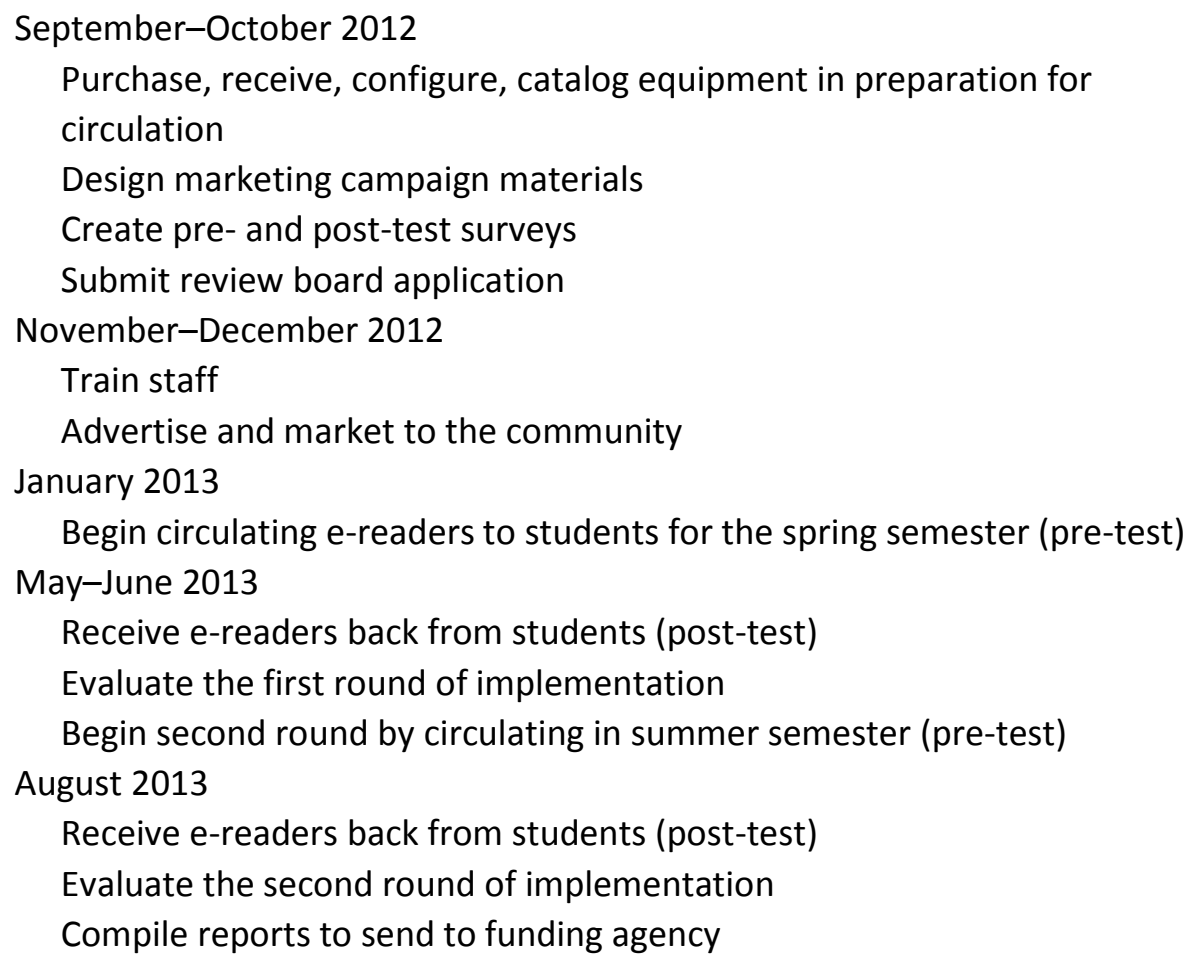

\section{MARKETING EFFORTS}

One of the most fun aspects of this project was the design of the marketing materials, as we used methods that were innovative for the library. There were many methods through which we publicized the service to our community. In working with our in-house communications and marketing department to come up with the best avenues for publicity, we were able to develop a comprehensive campaign involving posters, flyers, television slides, and other advertisements.

We used traditional locations for notifying students. Posters were installed in the library, the University Union, and in other common areas on campus (see Figure 1). The flyers were distributed to students in the library. Multiple display televisions in the University Union, libraries, and dormitories offered a space to advertise with slides. We did the obligatory website and Facebook announcements.

The most innovative marketing we did, however, took place in multiple cafeterias on campus: napkin holders. There are over 370 large napkin holders in cafeterias on our campus in which we placed notifications about the e-readers (see Figure 2). This was a first for the library, and a first for the campus. We were the first non-dining services unit on campus to use this avenue of publicity, and besides the signs in the library, it turned out to be the most popular spot where students learned of the program. 


\section{setyour own deadlines}

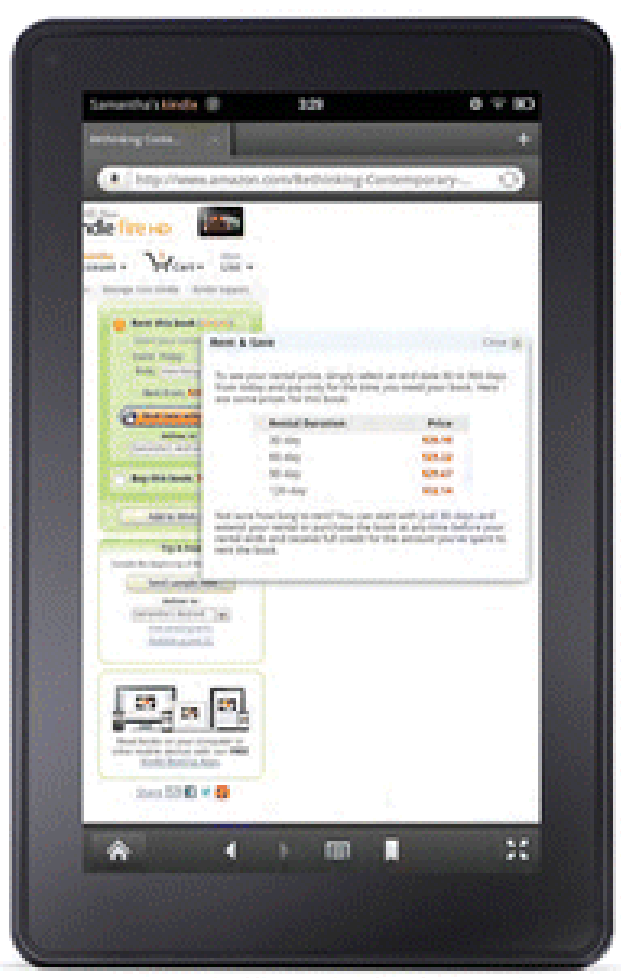

\section{CHECKOUT YOUR OWN KINDLE FIRE OR IPAD SO YOU CAN PURCHASE DIGITAL TEXTBOOKS}

Available this Spring at the Willis Library Information Desk Limited quantities available, contact Sian Brannon for more information

\section{UNT Libraries}

Figure 1. Poster advertisement.

Although fun to design, marketing was a challenge because of the stipulation that the library would not purchase the textbooks for the users but rather simply provide the necessary equipment. This was also a challenge and had to also be approved by the Institutional Review Board because it served as the "recruiting material" for the research. Marketing was too successful in a way, as we initially had a waiting list of eight people before circulation officially began. 


\section{Don't get weighed down}

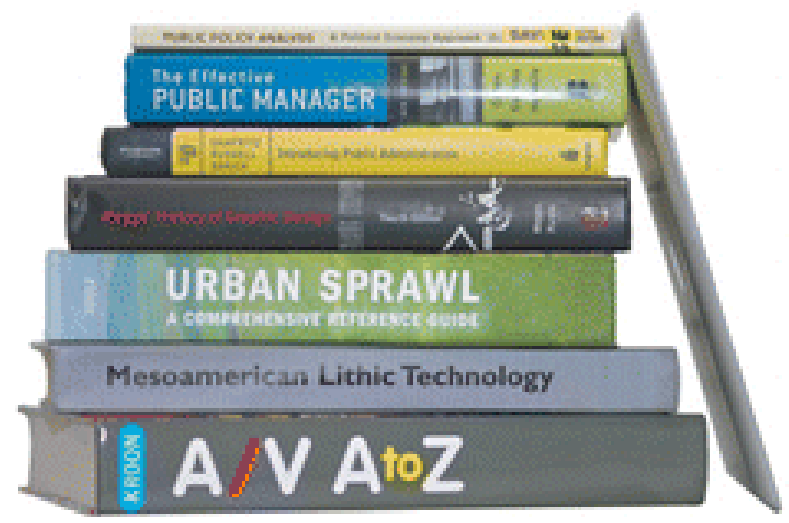

CHECKOUT YOUR OWN KINDLE FIRE OR IPAD SO YOU CAN PURCHASE DIGITAL TEXTBOOKS Available this Spring at the Willis Library Information Desk Limited quannities available, contact Sian Brannon for mare informotion UNT Libraries

Figure 2. Napkin holder marketing.

\section{EVALUATION}

The granting agency provided an outcome-based survey to be administered at the end of the circulation period. The researchers were required to use the questions provided. In the interest of saving our users' time and in reducing the survey fatigue already experienced on our campus, we added only one question to their survey. We changed the wording of the questions in order to adapt the survey to a pretest. Students were asked to rate the following statements from strongly disagree to strongly agree:

- This technology improved my access to information and/or materials.

- Using this technology allowed me to access information and/or materials previously not accessible to me.

- I was satisfied with the information and/or materials provided by this technology.

- This technology improved or enhanced my ability to meet my educational goals.

- This technology improved or enhanced my ability to meet my economic goals.

- This technology improved or enhanced my ability to meet my personal goals.

- Using this technology has expanded my awareness of the electronic resources available through the library.

The overall result of the program was that participants "agreed" or "strongly agreed" that the availability of e-readers made them more aware of library services and expanded their knowledge of electronic materials available in the library. We were unable to determine a statistical significance to prove that students were not buying electronic textbooks because they did not have access to ereaders. The scores on the pre- and post-test surveys for the majority of our questions were not significantly increased or decreased, but remained static (see Figure 3). 
Although there was no room for comments on the survey, we did receive some unsolicited feedback from participants via e-mail that was very encouraging:

I am a graduate student at UNT and I have been enjoying the use of an iPad this semester that I checked out through the e-reader program. It has made such a difference in my research efforts over the last semester!

This semester I have participated in this study. The access to the iPad that I am using has made my studies this semester far less stressful. With it, I have more efficient time management skills, and a constant access to the materials for my class. I immensely appreciate being able to use the device, and it is the only electronic I have that can access my textbooks. It has proven extremely helpful for research with the use of its browser as well. This summer I will be enrolled in classes here at UNT, three of which are online courses. I am employed by the University of North Texas Police Department as a security guard and work the night shift. The limited hours of the libraries on campus would be an unavoidable difficulty to my studies if I do not have access to a device such as this iPad.

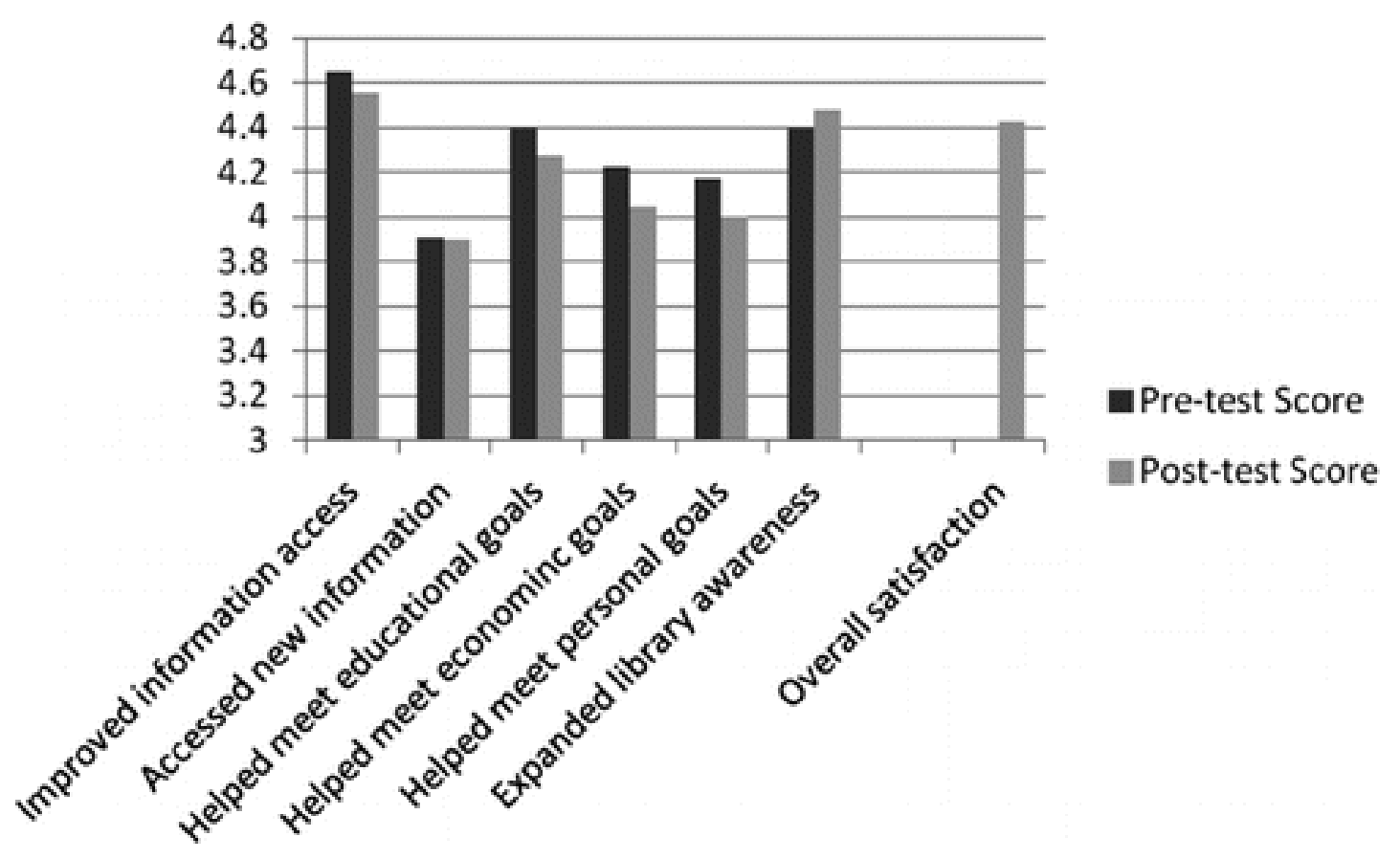

Figure 3. Pre- and post-test survey results.

I think that it is a great idea to make this technology available to all students. Outstanding use of funds, and I was very impressed that UNT is pioneering this project. 
The pilot program at UNT Libraries was very small, but there were several revelations that could help other libraries trying to build a similar service and will help further develop the project at UNT. The researchers presented the progress of the grant project at the American Library Association Annual Conference in June, 2013. The presentation included a list of "things we wish we'd done differently" and "issues to consider." These include the need to establish documented procedures for checkouts, waiting lists, and early returns. We advocate including a space on any assessment surveys for general comments.

The primary issue to address is the creation of policies and procedures for the implementation of the program. Detailed instructions on the circulation procedures will need to be developed and followed. These should include a form for student accountability if the equipment is damaged while checked out to them. Additional items to consider are procedures for managing the wait list, length of checkout, staff responsible for checkout, assessment surveys, how to handle early returns, who is eligible to check out the equipment, and any parameters on use of the equipment. We established a lot of our procedures using the framework of the procedures that we use for laptop checkouts. Faculty, staff, and community members were not allowed to check out the e-readers, only students. The library's computer systems staff were designated as the staff responsible for circulating the equipment because they already had a system set up for electronic equipment.

Another issue to consider is how staff will be trained on the program. Staff who will be performing the circulation of the e-readers will be trained on the policies. Staff members who work at the service desks will be informed about the service and provided with some simple answers to frequently asked questions. This will allow them to direct students to the appropriate area for checking out the equipment but can also be a great marketing tool. The front-line staff can promote the program to students who are looking for textbooks.

In addition to using the front-line staff for marketing, anyone else conducting such a program should investigate all available marketing opportunities. We were able to take advantage of a unique servicethe advertisements on napkin holders in cafeterias. This promotion resulted in a lot of inquiries about the service.

Something that we neglected to plan for was students returning the equipment before the end of the semester. Because we were testing the theory that students were not purchasing e-textbooks because they did not have access to an e-reader, we made the decision to check the equipment out for the entire semester. A parameter was defined that the equipment was to be used for a digital textbook for one of their classes. The honor system was used to enforce this restriction. We knew that with the limited supply, we would probably run out of e-readers, but we did not anticipate that all of them would be checked out so quickly. We did not make plans for a waiting list because we did not anticipate that students would return the equipment mid-semester. When this occurred during the spring semester, we had to improvise. There were no early returns in the summer semester.

As a research project, our pre- and post-tests were developed based on the needs of our granting agency. In retrospect, we wish we had allowed a space for comments from users. We did receive some comments via e-mail. The personal stories related in these communications are great ways to demonstrate to the library administration the value of sustaining this service. 


\section{SUSTAINABILITY}

As found in previous studies, "not every student has the knowledge, the fiscal means, the actual need or desire, or the circumstances to use e-books" (de Oliveira, 2012, p. 555). That was the impetus driving the original grant application. The researchers set out to eliminate the knowledge and fiscal barriers to e-reader and e-textbook use and provide the technological means for students. With equipment purchased, two rounds of circulation complete, and a customer base still lining up to use the e-readers, the project has fallen naturally into a replicable desired service that we plan to sustain.

Based on the small sample of users, we recommended to the library administration that the circulation of e-readers to students continue in a modified way. We are continuing to circulate the equipment to students only but will not restrict the usage to digital textbooks. We will not be conducting pre- and post-test surveys for the time being, as that would require more Institutional Review Board review. Instead, we are working on a more enhanced study to instruct humanities faculty on how the e-readers can be incorporated into their courses and to follow recommendations in developing competencies for faculty and librarians related to e-reader use in instruction, such as knowledge of various devices, understanding of digital rights management issues, and awareness of e-reader usage on campus (Zauha \& Ragains, 2011).

\section{REFERENCES}

1. Ahlroos, P., \& Hahto, J. (2012). The e-reader-An educational or an entertainment tool? E-readers in an academic setting. Liber Quarterly: The Journal of European Research Libraries, 21, 249-261.

2. Behler, A., \& Lush, B. (2011). Are you ready for e-readers? The Reference Librarian, 52, 75-87.

3. de Oliveira, S. M. (2012). E-textbooks usage by students at Andrews University. Library Management, $33,536-560$.

4. Foasberg, N. (2011). Adoption of e-book readers among college students: A survey. Information Technology and Libraries, 30, 108-128.

5. Goodwin, S., Shurtz, S., Gonzalez, A., \& Clark, D. (2011). Assessing an e-reader lending program: From pilot to mainstream service. Library Review, 61, 8-17.

6. Jung, J., Chan-Olmsted, S., Park, B., \& Kim, Y. (2011). Factors affecting e-book reader awareness, interest, and intention to use. New Media \& Society, 14, 204-224.

7. Kemp, J., Lutz, E., \& Nurnberger, A. (2012). E-readers on trial: Qualitative results from an academic library pilot project. Journal of Electronic Resources Librarianship, 24, 189-203.

8. McCaslin, D. (2013). Collection building through patrons: Caltech Library's Kindle program. Collection Management, 38, 172-191. 
9. Nicholas, D., Rowlands, I., \& Jamali, H. (2010). E-textbooks use, information seeking behavior and its impact: Case study business and management. Journal of Information Science, 36, 263-280.

10. Rainie, L., \& Duggan, M. (2012). E-book reading jumps; print book reading declines. Retrieved from http://libraries.pewinternet.org/2012/12/27/e-book-reading-jumps-print-book-reading-declines/

11. Rojeski, M. (2012). User perceptions of ebooks versus print books for class reserves in an academic library. Reference Services Review, 40, 228-241.

12. Tees, T. (2010). Ereaders in academic libraries-A literature review. The Australian Library Journal, 59, 180-186.

13. University of North Texas. 2012-2013 Fact Book. Retrieved from http://institutionalresearch.unt.edu/sites/default/files/Fact Book-2012-2013.pdf.

14. Weisberg, M. (2011). Student attitudes and behaviors towards digital textbooks. Publishing Research Quarterly, 27, 188-196.

15. Westfall, L. (2011). eReaders and eBooks, are students using them? Retrieved from http://www.fastweb.com/student-life/articles/3106-ereaders-and-ebooks-are-students-using-them

16. Zauha, J., \& Ragains, P. (2011). Is there a text in this class? Communications in Information Literacy, $5,68-73$ 